\title{
Dr. Thomas Willis and his 'Circle' in the Brain
}

\section{PVS Rana, MD, DM}

Department of Medicine

(Neurology)

Manipal Teaching Hospital

Manipal College of Medical Sciences

Pokhara, Nepal

\author{
Address for correspondence: \\ PVS Rana, MD, DM \\ Department of Medicine \\ (Neurology) \\ Manipal Teaching Hospital \\ manipal College of Medical Sciences \\ Pokhara, Nepal \\ Email: rananirmal@fewanet.com
}

With the advances in microneurosurgery and the ability to tackle diseases of the intracranial arteries at the base of the brain (often referred to as the Circle ofWillis) surgically more effectively, accurate knowledge of the intracranial vascular anatomy is increasingly important. Although Dr. Thomas Willis is best remembered for the accurate description of arterial anastomosis at the baseof the brain, his contribution to neuroanatomy, physiology and medical science in general is vast, and several diseases bear his name. In this article an attempt has been made to review the life of Dr. Willis followed by a short description of the "Circle of Willis."

Key Words: anatomy, Circle of Willis, Dr. Thomas Willis

Received, December 18, 2004

Accepted, December 30, 2004

\begin{abstract}
"Anne Green was a 22-year-old woman who had been employed as a housemaid by Sir Thomas Read in Oxfordshire. She was probably seduced by his grandson, who turned her down when she became pregnant. The unlucky girl gave birth to a premature child whom she concealed. The dead boy was found, however, and Anne Green was accused of the murder of her own child. She was sentenced to die by hanging and the execution took place on December 14, 1650. Anne Green climbed the ladder up to the gallows, where the rope was laid around her neck. Then she was pushed off the ladder. While the body was hanging there people came forward to pinch her breasts, or amuse themselves by hanging on the legs. This was the usual practice, then, so that the person would die faster. The attending court usher now feared that the rope might break, and urged the spectators to leave the body alone. After about half an hour, the body of Anne Green was presumed dead and placed in a coffin and was taken home to Dr. William Petty, lecturer in anatomy at a university, as 'corpses were very difficult to get for anatomy dissection during that period.'

When the doctors, one of whom was Dr. Thomas Willis, opened the coffin for dissection, the 'corpse' took a breath. The plan for dissection was immediately replaced by resuscitation. Treatment included keeping the body in an upright position, pouring hot drinks into the mouth, tickling the neck so as to induce coughing, rubbing the hands and feet and bloodletting. Anne Green started to make a remarkable recovery and in 12 hours, she was able to vocalize and was sent home in two days. In one month she was fully restituted except for slight retrograde amnesia. She was subsequently set free and lived for 15 years after her'famous execution. '3,5",
\end{abstract}

Dr. Thomas Willis ${ }^{3,9}$ (Figure 1) came from a family of small farmers and rose to become a brilliant physician and anatomist. He was the eldest of the three sons of Rachel Howell and Thomas Willis, born on 27th January, 1621 in Great Bedwyn, Wiltshire. He did his basic schooling at the school of Edward Sylvester in Oxford and matriculated from university from Christ Church College on March 3, 1637. He continued his further studies while working as a servitor to one of the Cathedral's canons and completed his BA in 1639 and MA in 1642. He served in the Royalist army from 1643 to 1646. During this period he continued his medical studies obtaining his MB degree in 1646 . He was cofounder of the Royal Society (1660) and became an Honorary Fellow of the Royal College of Physicians in 1664. He started his practice in Oxford but shifted to London in 1667 at the invitation of the Archbishop of Canterbury and established a very prosperous practice. His patients included members of the royal family. From 1660 onwards till his death, Thomas Willis was Sedleian Professor of Natural Philosophy. He married the sister of John Fell, Dean of Christ Church. He had to bear the untimely death of six of his eight children and of his two brothers. His wife died in 1670 . He developed pleurisy and died in 1675 at the age of 54 and was buried in the transept of Westminster Abbey.

His personal tragedies failed to deter him from pursuing his goals. He had an astonishing knowledge of anatomy and astute observational powers. During his first year's practice in London, he described six diseases unknown to medical science and wrote many books. The book "Cerebri anatomi" (The anatomy of Brain and Nerves) published in 1664 is considered one of the classic publications of English medicine. In addition to his famous work on cerebral circulation that is still called the "Circle of Willis" (beautifully illustrated by Wren's engraving (Figure 2), in this book 


\section{Dr. Thomas Willis}

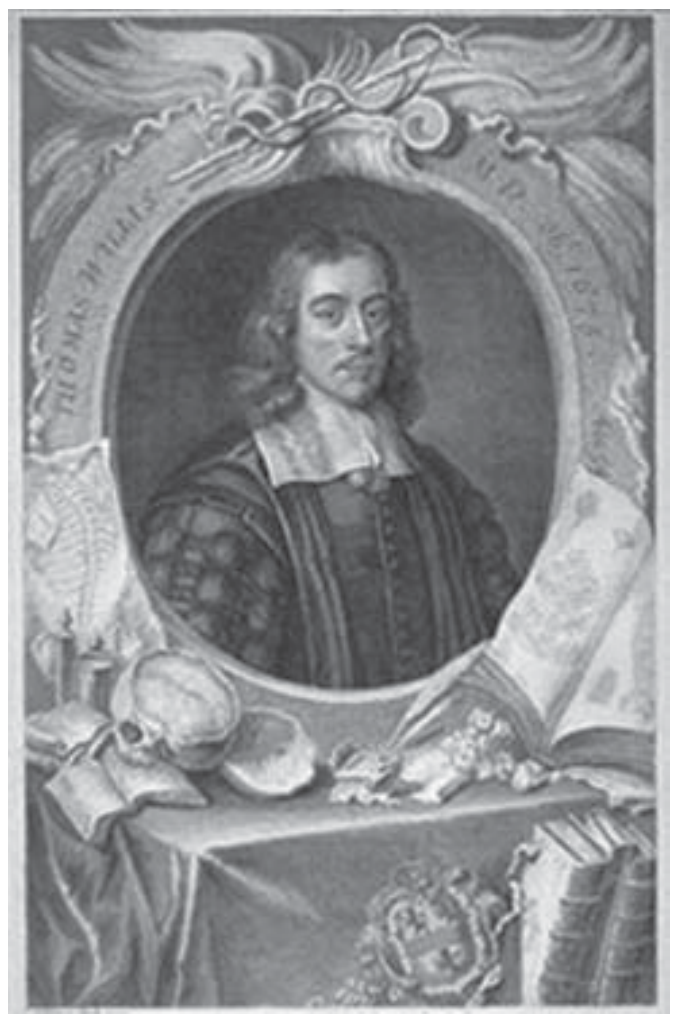

Figure 1. Dr. Thomas Willis. [With permission from SenGupta RA, McAllister VL (eds). Anatomy of cerebral vessels in Subarachnoid Hemorrhages. Springer-Verlog, Berlin, Heidelberg, New York, 1988]

he also described for the first time the term "reflex action". His other important publications included Pathologiae cerebri et Nervosi Generis Specimen (An Essay on the Pathology of the Brain and Nervous Stock) in 1667, Deamina Brutorum (Discourses concerning the Souls of Brutes) in 1672 and Pharmaceutice rationalis in 1674. He was the first to number the cranial nerves in the order in which they are now enumerated, including the spinal accessory nerve which he discovered. His other medical contributions included a description of Typhus fever, corpora striata, lentiform nucleus, optic thalamus, pons (which he named "annular protuberance”) and the mamillary bodies. In the cerebellum he described the arborescent arrangement of white and gray matter and gave a good account of the carotid artery and its communications with the basilar artery. Dr. Thomas Willis proposed that the corpus striatum received all sensory information while the corpus callosum was associated with imagination and the cerebral cortex with memory (Deamina Brutorum, 1672) and that the choroids plexus was responsible for absorption of cerebrospinal fluid (CSF). He contributed to the acceptance of quinine and reintroduced colchicine therapy for gout (Pharmaceutice rationalis, 1674-75). Many eponyms are associated with Dr. Willis, i.e. Baldwin-Gardener-Willis operation (a phenomenon associated with tubercular bacilluses), Paracusis of Willis (the ability to hear better in noise), Willis' cords (fibrous cords crossing the superior longitudinal sinus transversely), Willis' disease I (historic term for diabetes mellitus), Willis' disease II (asthma), Willis' gland (corpora albicantia: obsolete term), Willis' nerve (the ophthalmic branch of the fifth nerve) and the most famous the 'Circle of Willis' (the circle of anastamosed arteries at the base of brain). In addition, Dr. Thomas Willis will also be remembered for the resuscitation of Anne Green in 1650 (vide supra), who was brought to him for dissection after her execution by hanging. ${ }^{3,5}$ This apparent resurrection gave him a lot of fame during his time and was a source of envy to his contemporary physicians. His works are an important part of the history of Medicine and has placed him amongst the immortals in the field of Medicine.

\section{Circle of Willis}

Major arteries supplying the brain, paired internal carotid and vertebral arteries, form a unique anastomosis, the "Circle of Willis" named after Dr. Thomas Willis who first accurately described it and provided its physiological significance. Anteriorly, the anterior cerebral arteries (from internal carotids) are joined by the anterior communicating artery. Posteriorly, the basilar artery divides into two posterior cerebral arteries each joined to the ipsilateral internal carotid by a posterior communicating artery.

The vessels of the "Circle of Willis" show wide variation in calibers and sometimes even are absent. The variations have been studied, ${ }^{1,4,6}$ and are shown in Figure 3. ${ }^{8}$ There is normally no mixing of the opposing stream of blood which meets in the posterior communicating arteries at points at which the pressure of the two are equal. The same applies in the middle of the anterior communicating artery. ${ }^{2}$ Its importance is seen in two clinical circumstances, i.e. incidental detection of occlusion of major arteries in

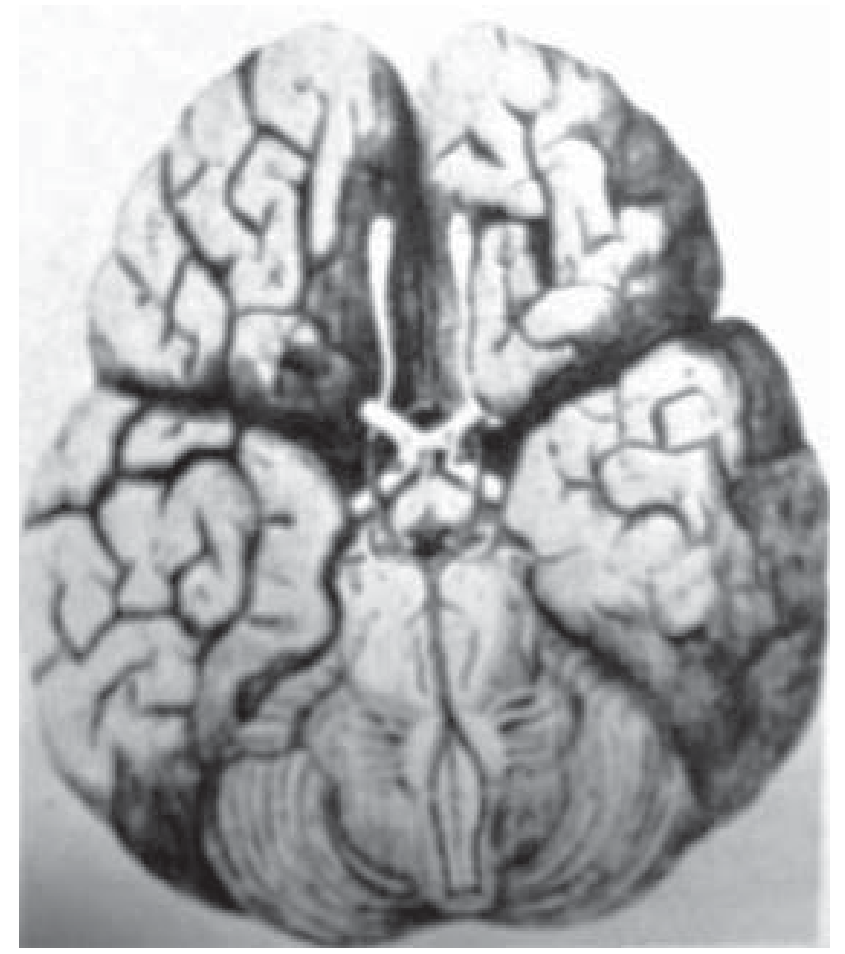

Figure 2. Wren's engravings of the "Circle of Willis." [With permission from SenGupta RA, McAllister VL (eds). Anatomy of cerebral vessels in Subarachnoid Hemorrhages. Springer-Verlog, Berlin, Heidelberg, New York, 1988] 


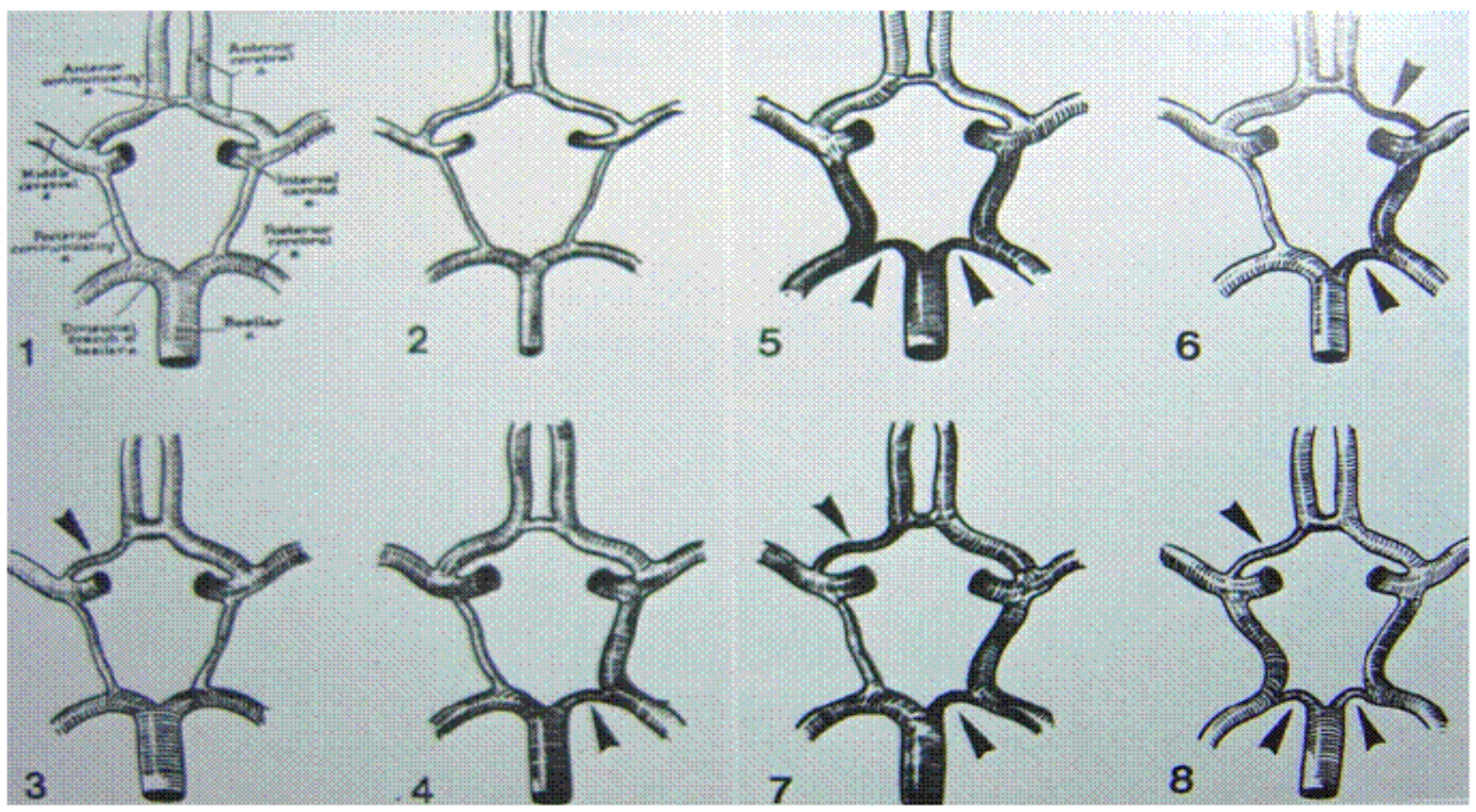

Figure 3. Different variations in the "Circle of Willis." [ With permission from SenGupta RA, McAllister VL (eds). Anatomy of cerebral vessels in Subarachnoid Hemorrhages. Springer-Verlog, Berlin, Heidelberg, New York, 1988]

asymptomatic cases and when surgical occlusion of a major vessel is contemplated. Fields, et al., (1965) ${ }^{4}$ have summarized the above studies. Though there is a complete circle in $90 \%$ of cases, in most one or other of the vessels is sufficiently narrowed to impair its role as a collateral route. Angiographic evidence indicates that such defective or absent circulation is seen in about a third of such cases. ${ }^{7}$ Hence one cannot presume existence of an effective arterial circle. Angiography, therefore, is a must when planning surgery on its feeders. Anomalies of the "Circle of Willis" may play a role in the development of aneurysm by producing hemodynamic changes in blood flow and inducing strain on the weak point of the arteries (the bifurcation). The physiological alteration in blood flow may have a prognostic significance in aneurysmal surgery. ${ }^{8}$

The different variations in the components of the "Circle of Willis" are described as follows: Type I: Normal (18\%); Type II: Smal but fully formed posterior communicating arteris (6\%); Type III: Unilateral hypoplasia of anterior cerebral artery (25\%); Type IV: Unilateral hypoplasia of posterior cerebral artery with posterior communicating artery developing partially or fully from internal carotid artery (16\%); Type V: Bilateral hypoplasia of posterior communicating artery with partial or complete origin of both posterior communicating arteries from ICA (11\%); Type VI :Combination of Type III with Type IV on same side (8\%); Type VII: combination of Type III with type IV on contralateral side ( $8 \%)$; and Type VIII: Combination of Type III and Type V ( $8 \%)^{6}{ }^{6}$

\section{References}

1. Alpers BJ, Berry RG, Paddison RM: Anatomical studies of the Circle of Willis in normal brain. Arch Neurol Psychiat 81:409-418, 1953

2. Du Plessis DJ (ed): A Synopsis of Surgical Anatomy. Ed 11. John Wright \& Sons Ltd, Bristol. 1975, pp 552

3. Enersen OD: 1994-2001."Thomas Willis" www.whonamedit.com [Accessed December 5, 2004]

4. Fields WS, Bruetman ME, Weibel J (eds). Collateral circulation of brain. Williams and Wilkins, Baltimore, 1965

5. Hughes JT: Miraculous deliverance of Anne Green. An Oxford case of resuscitation in seventeenth century. BMJ 285: 1790-1793, 1982

6. Riggs HE, Rupp C: Variations in form of Circle of Willis. Arch Neurol Psychiat 8:8-14, 1963

7. Sedzmir CB: An angiographic test of collateral circulation through the anterior segment of Circle of Willis. J Neurol Neurosurg Psychiat 22: 64-68, 1959

8. SenGupta RA, McAllister VL (eds). Anatomy of cerebral vessels in Subarachnoid Hemorrhages. Springer-Verlog, Berlin, Heidelberg, New York, 1988

9. Thomas Willis Wikipedia: the Free Encyclopedia. Retrieved from "http://en.wikipedia.org/wiki/Thomas Willis" [Accessed December 25, 2004] 